\title{
Breast cancer burden in central Sudan
}

\author{
This article was published in the following Dove Press journal: \\ International Journal of Women's Health \\ 28 February 2010 \\ Number of times this article has been viewed
}

\section{Elgaili M Elgaili' \\ Dafalla O Abuidris ${ }^{2}$ \\ Munazzah Rahman ${ }^{3}$ \\ Arthur M Michalek ${ }^{4}$ \\ Sulma I Mohammed ${ }^{3,5}$ \\ 'Faculty of Medicine, Department of Pathology, University of Gezira, Sudan; ${ }^{2}$ Radiation Oncology Department, Institute of Nuclear Medicine and Oncology, University of Gezira, Sudan; ${ }^{3}$ Department of Comparative Pathobiology, Purdue University, West Lafayette, IN USA; ${ }^{4}$ Roswell Park Cancer Institute, Buffalo, NY, USA; ${ }^{5}$ Purdue Cancer Center, Purdue University, West Lafayette, IN, USA}

Correspondence: Sulma I Mohammed Department Comparative Pathobiology, Purdue University, West Lafayette, IN 47907, USA

$\mathrm{Tel}+\mathrm{I}-765-494-9948$

Fax $+1-765-494-9830$

Emailmohammes@purdue.edu
Abstract: Breast cancer is a worldwide disease resulting in many deaths. Although breast cancer incidence is lower in Sub-Saharan African countries than in developed countries, African women are more likely than women in the developed world to be diagnosed at later stages of the disease and, thus, are more likely to die from it. This is due to the lack of awareness by women, accessibility to screening methods, and availability of African-based research findings that would influence decision making at the governmental level. This descriptive study was undertaken to shed light on the type, stage and age distribution of breast cancer at diagnosis in women living in central Sudan encompassing al-Gezira, Blue Nile, White Nile, and Sennar States. Cases comprised 1255 women from central Sudan diagnosed with breast cancer and referred to and treated at Institute of Nuclear Medicine, Molecular Biology, and Oncology, from January 1999 to December 2006. Data revealed that $74 \%$ of the women were $<50$ years old or premenopausal. Invasive ductal carcinoma was the most common pathology $(82 \%)$ and women presenting with stage III or higher tumors that had already metastasized, while ductal carcinoma in situ was the least prevalent $(0.5 \%)$ finding. Estrogen and progesterone receptors expression were performed on a limited number of samples and the overwhelming majority of cases were observed to be negative for estrogen and progesterone receptors expression.

Keywords: female breast cancer, estrogen receptor, progesterone receptor, epidemiology, Africa

\section{Introduction}

Breast cancer is the most commonly diagnosed cancer in women worldwide, and is second only to lung cancer as the leading cause of cancer deaths. ${ }^{1}$ Although, the incidence of breast cancer in Sub-Saharan African counties is low compared that in developed countries, ${ }^{2}$ the cancer picture in Sub-Saharan Africa and especially in Sudan is changing. Lately, breast cancer incidence and mortality has been rising.

Breast cancer in African women is characterized by younger age at onset, advanced stage at diagnosis, and consequently poor prognosis. For example in Nigeria, about two-thirds of women with breast cancer present with advanced stage disease. ${ }^{3,4}$ The reason for these unfavorable breast cancer presentations is reported to be the delay by patients presenting to the hospitals, due to ignorance, superstition, a skeptical attitude towards western medicine, and dependency on traditional medicine, ${ }^{5,6}$ in contrast to the industrialized world where early detection by mammographic screening and greater awareness by women has resulted in early detection. Early detection plus adjuvant chemotherapy has greatly increased survival rates for breast cancer patients. 
In the developed world assessment of hormonal receptors expression status is required to determine patient eligibility for hormonal therapy. However, in the developing countries clinicians administer hormonal therapy without any knowledge of their patient's receptors status. Estrogen receptors (ER) and progesterone receptors (PR) expression status is not routinely determined in the developing countries because of limited resources and the relatively high cost of testing. However, it should be noted that in a few studies conducted in Africa that examined ER and PR expression status, most African women were observed to have estrogen and progesterone negative tumors. ${ }^{7-9}$

This descriptive study was undertaken to shed the light on the type, stage and age distribution of breast cancer at diagnosis in women living in central Sudan encompassing al-Gezira, Blue Nile, White Nile, and Sennar States.

\section{Material and methods}

The central region of Sudan comprises four states including Blue Nile, al-Gezira, Sennar, and White Nile. Each of these states has population ranging from 600,000 to $3,797,000$, the majority living in the capital regions and the rest in surrounding rural areas. Breast cancer cases diagnosed in these states are referred for treatment to the Institute of Nuclear Medicine, Molecular Biology and Oncology (INMO) at Gezira University located in Wadmedani in alGezira State. Data presented in this study were collected from medical reports from these patients $(\mathrm{N}=1255)$ referred to and treated at the INMO during the period January 1999 to December 2006. Data were entered into a computerized database with the approval of the INMO Institution Review Board.

\section{Pathology evaluation}

Data on age at diagnosis, tumor pathology, stage of disease, and patient residence (urban/rural), were recorded. Tumors were classified according to TNM classification which based on size of the primary tumor and presence of metastatic regional lymph nodes and/or of distant metastases. No data on grade were available (this was not a common service at that time at these local facilities). Whenever possible, tumor specimens were stained immunohistochemically for estrogen and progesterone receptor expression.

\section{Immunohistochemistry (IHC)}

Immunohistochemistry was done according to the standard avidin-biotin-peroxidase complex method. Briefly, histologic sections (5 Am) with neoplastic breast tissue were cut from formalin-fixed, paraffin-embedded tissues and mounted on positively charged Superfrost slides (Fisher Scientific). Tissue sections were deparaffinized and rehydrated in graded ethanol. Antigens were retrieved by steaming in $0.01 \mathrm{~mol} / \mathrm{L}$ citrate buffer ( $\mathrm{pH}$ 6.0) in a water bath at $95^{\circ} \mathrm{C}$ for $10 \mathrm{~min}$. Tissues were then blocked for endogenous peroxidase in 3\% hydrogen peroxide in methanol and for nonspecific binding in tris buffered saline containing $0.3 \%$ Triton X-100, 0.2\% saponin, and $0.5 \%$ blocking agent (NEN Life). Tissues were incubated overnight at $4{ }^{\circ} \mathrm{C}$ in the following antisera: ER-a monoclonal mouse anti-human antibody (ID5) at 1:25 dilution, progesterone receptor antibody (IA6) at 1:40 dilution (Novocastra Ltd) followed by biotinylated horse anti-mouse or goat anti-rabbit secondary antibodies (Vector Laboratories).

The chromogen was 3,3-diaminobenzidine (Vector Laboratories). Sections were counterstained in hematoxylin (Richard Allen Scientific) and then coverslipped in 50:50 xylene/permount (Fisher Scientific).

All slides were reviewed independently. Expression of ER and PR in tumor tissues was analyzed and reported as the percentage of epithelial cells with positive staining. The intensity of ER and PR immunostaining was graded on a scale of 0 to 3 where $0=$ no staining, $1=$ weak staining, $2=$ moderate staining, and 3 = strong staining.

\section{Statistical analysis}

Morphologic lesions were expressed with descriptive statistics. Immunohistochemical data were analyzed with nonparametric methods on semi-quantitative IHC scores using SPSS statistical software

\section{Results}

\section{Age}

Of the 1255 women treated at the INMO between the period 1999 to $2006,279(22.23 \%)$ were between ages 35 and 40 years. About 927 of the 1255 (74\%) breast cancer patients were premenopausal (age $<50$ years) while only $26 \%$ were postmenopausal (older than 50 years) (Figure 1).

\section{Tumor histopathology}

Infiltrating ductal carcinoma constituted the majority of the breast cancers diagnosed (1029 of $1255 ; 82 \%)$. Other subtypes of breast disease such as infiltrating medullary ductal carcinoma, infiltrating lobular carcinoma, malignant connective tissue tumor, infiltrating mucinous 


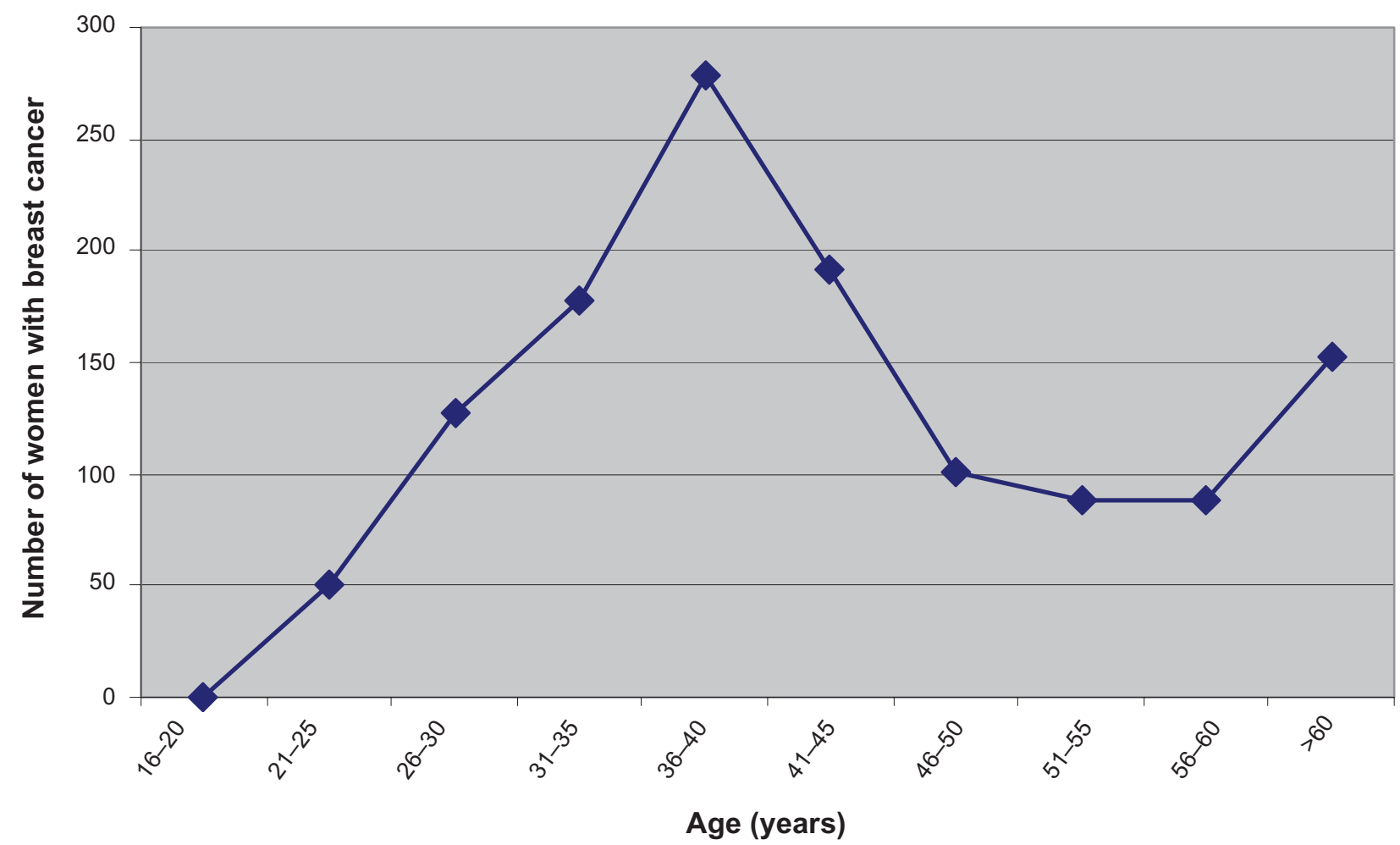

Figure I Breast cancer age distribution ( $\mathrm{N}=1255)$. This graph shows age distribution of breast cancer in central Sudan. Women in central Sudan diagnosed with breast cancer were premenopausal (age $<50$ years) while only $26 \%$ were postmenopausal (older than 50 years).

ductal carcinoma, infiltrating papillary ductal carcinoma, as well as ductal carcinoma in situ, malignant phylloide tumor, infiltrating squamous cell carcinoma, and carcinoid tumor represented a small fraction of the diagnosed breast diseases (Table 1).

\section{Tumor stage}

According to the TNM staging criteria the majority of women presented with late disease that had already metastasized IV (T4N4M1; 24.6\%), IIIA (T3N2M0; 18.0\%), IIIB (T4N4M0;

Table I Histopathological characteristics of breast cancer in women from central Sudan

\begin{tabular}{lll}
\hline Histological type & $\mathbf{N}$ & $\%$ \\
\hline Invasive ductal carcinoma & 1029 & 82.0 \\
Infiltrating medullary ductal carcinoma & 91 & 7.3 \\
Infiltrating lobular carcinoma & 79 & 6.3 \\
Malignant connective tissue tumor & 14 & 1.1 \\
Infiltrating mucinous ductal carcinoma & 13 & 1.0 \\
Malignant phylloide tumor & 9 & 0.7 \\
Infiltrating papillary ductal carcinoma & 7 & 0.6 \\
Ductal carcinoma in situ & 6 & 0.5 \\
Infiltrating squamous cell carcinoma & 5 & 0.4 \\
Carcinoid tumor & 2 & 0.2 \\
\hline
\end{tabular}

18.1\%), IIA (T2N0M0; 8.2\%), IIB (T3N0M0; 19.3\%), I (T1N0M0; 11.3\%), 0 (0.5\%) (Figure 2). About 726 of the $1255(58 \%)$ women resided in rural areas and 529 of 1255 $(42 \%)$ women in the State capitals or surrounding areas (urban areas). Women living in the rural areas presented significantly more often with advanced metastatic disease stage III or higher $(P=0.002)$ than women living in urban areas (Figure 3).

\section{Estrogen and progesterone receptor status}

Information on ER and PR status was available for only 50 patients. Tumor tissues were found to be predominantly estrogen negative $(34 / 50 ; 68 \%)$ or progesterone negative $(35 / 50 ; 70 \%)$. A smaller percentage of cases presented as ER-positive and PR-positive (10/50; 20\%). ER and PR status could not be determined in 2 cases.

\section{Discussion}

Despite the fact that breast cancer has been reported to be the leading malignancy according to estimate data from GLOBOCAN, ${ }^{10}$ studies on breast cancer in Sudan have been limited. The reasons for this include the lack of 


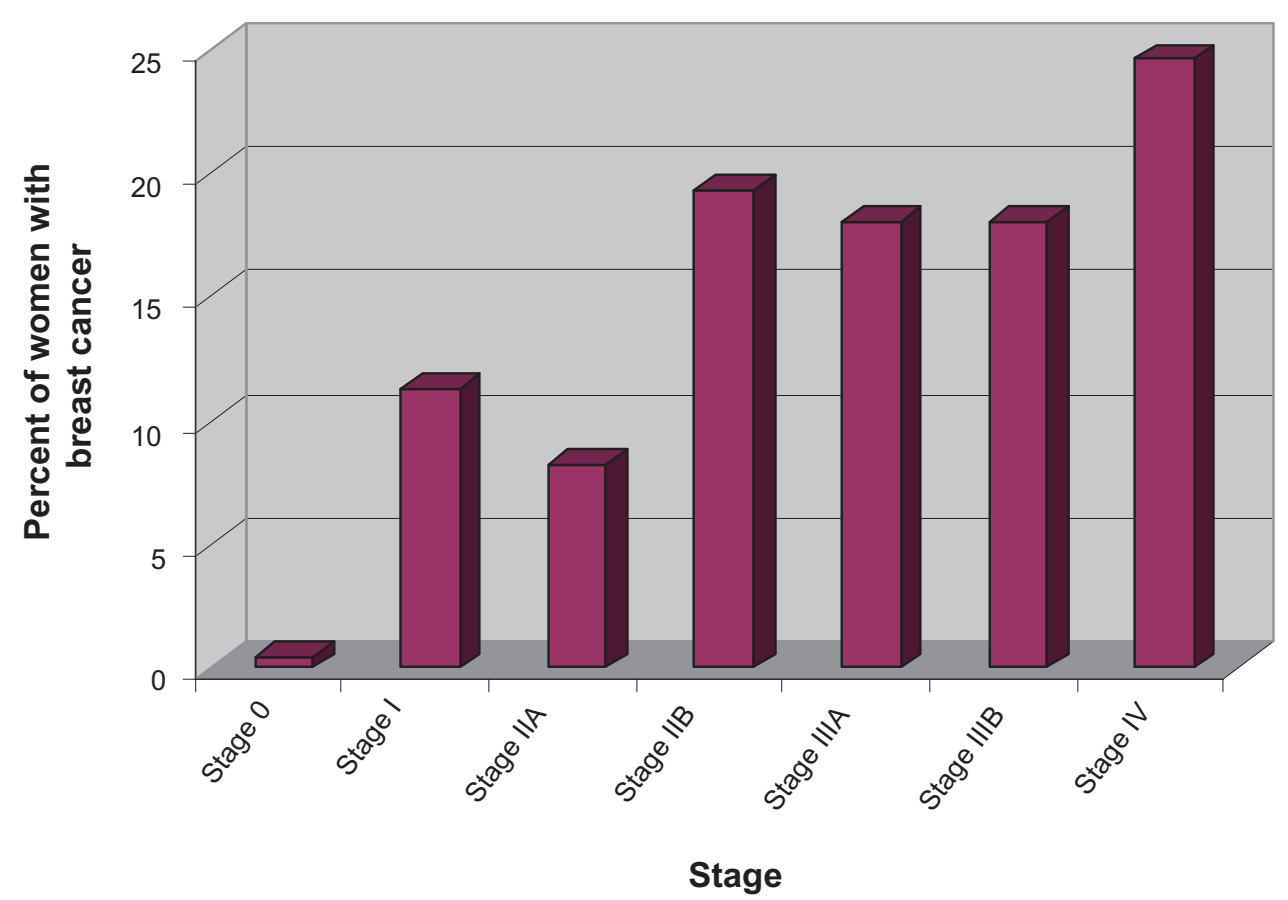

Figure 2 Breast cancer by stage. The graph shows that women living in central Sudan present to the local medical facility with late stage tumors III and higher.

population-based cancer registry as well as lack of research resources (manpower and financial). The current study analyzed and presented data collected at the local medical facilities in the Sudan and entered in computerized database at the INMO when women were referred and treated at the Institute. While our study population is far from comprehensive it is thought to represent the totality of breast cancer in this area. Data on 1255 patients treated between 1999 and 2006 were examined. Of the 1255 patients examined we found that $74 \%$ were premenopausal women (aged 50 and younger) and 26\% were postmenopausal, indicating early onset of breast cancer in women living in that area. This observation is consistent with the literature and has been reported in several other studies conducted in sub-Saharan Africa. ${ }^{11-13} \mathrm{~A}$ higher incidence of breast cancer in younger women has also been observed in women of African descent residing in western countries. ${ }^{14,15}$ Similarly, in a recent study conducted to examine data collected from British women, it has been shown that black British women were diagnosed with breast cancer at a much younger age (average difference 21 years) compared to their white counterparts. ${ }^{16}$ The reasons for the younger age distribution of African women with breast cancer deserve additional study. However, Pathak et al ${ }^{17}$ investigated this issue in AfricanAmerican women living in the United States. Pathak and his colleagues correlated the short-term increase in breast cancer risk occurs in the postpartum period with premenopausal breast cancer risk and concluded that the higher prevalence of early childbearing among African-American when compared with Caucasian-American women may account for the higher incidence of early-onset breast cancer. In another study Palmer et al ${ }^{18}$ reported that multiparity increased breast cancer risk prior to age 45 but offer a protective effect after age 45 years. These factors may explain the age distribution of breast cancer in African women who tend to have multiple children at a younger age.

Infiltrating ductal carcinoma was the most common and ductal carcinoma in situ (DCIS) was among the least common histopathological diagnosis noted in this study. The majority (88.2\%) of women presented with Stage III or higher tumors. This has also been observed in studies conducted in other African countries, wherein a majority of the cases were observed to be invasive ductal carcinoma. ${ }^{13,19}$ These findings may be attributable to the fact that patients ignore symptoms and do not access medical care at an early date. This might be due to a lack of education, a skeptical attitude towards western medicine, cultural mores that ostracize and alienate diseased individuals, a dependency on traditional medicine, ${ }^{20}$ limited access to medical care (financial or otherwise), distance to the medical centers, availability of boarding and lodging close to the centers, the fear of being perceived as 


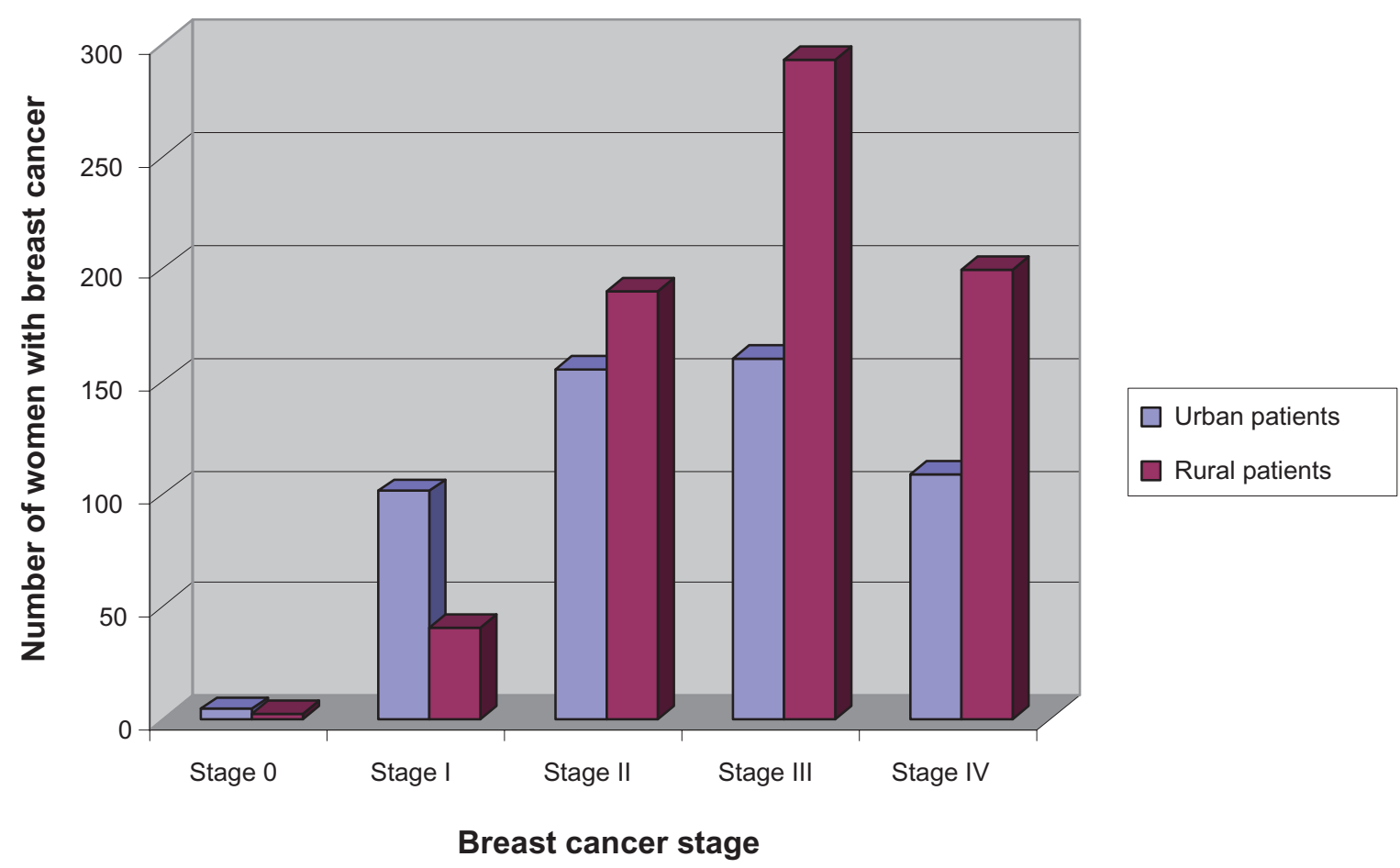

Figure 3 Breast cancer stage by residency. Women living in rural areas present with late stage tumors III and higher while women living in urban areas present with early stage tumors.

a burden to relatives and friends, financial aspects of undergoing testing and treatment, and various other factors that play a role in prolonging the patients' decision to seek medical treatment. ${ }^{21,22}$ Even if women managed to overcome all these challenges, there is still the issue of whether mammography and effective treatment will be available to them. These factors are compounded by a lack of governmental subsidies dedicated to improving diagnosis and treatment.

Hormone receptor status was available for only 50 patients (4\%). The reason is that testing is performed at only one private laboratory. Patients are presented with their breast biopsy in a formalin jar and advised to take it to a laboratory in Khartoum for analysis. The laboratory is a 3-hour drive from INMO. The total cost for the bus ride, food and lodging, and laboratory analyses is equivalent to 1 month's income for one Sudanese family. Very few women can afford this test so they simply take the sample home and bury it. Many of these women have been diagnosed with invasive metastatic cancers, have no money or prospects for treatment, and believe that spending more money on additional tests is a waste and is taking money away from the support of their family. Moreover, ER status means nothing to many of the physicians as these women present with late stage tumors that had metastasized.
For those women who did undergo additional hormonal testing, a high percentage of tumors were found to not express estrogen and progesterone receptors (ER-negative $=68 \%$; PR-negative $=70 \%$ ). This finding is similar to observations previously made in other African studies. One such study evaluating hormonal receptor status found that $\mathrm{ER} / \mathrm{PR}$-negative tumors were more predominant in breast cancer cases from Tanzania. ${ }^{23}$ Analysis of ER/PR status in Nigeria showed similar results wherein $75 \%$ of the cases presented with ER-negative and $72 \%$ of cases PR-negative tumors. ${ }^{24}$ Similar hormonal status expression was observed in African-American women who presented with ER-negative tumors. ${ }^{25}$

In conclusion, this study suggests that the typical breast cancer patient in central Sudan tends to be a younger, premenopausal woman living in a rural area and presenting with advanced disease likely to be ER/PR negative.

\section{Disclosures}

The authors disclose no conflicts of interest.

\section{References}

1. Jemal A, Siegel R, Ward E, Hao Y, Xu J, Thun MJ. Cancer statistics. CA Cancer J Clin. 2009 Jun 9. [Epub ahead of print].

2. Parkin DM, Pisani P, Ferlay J. Global cancer statistics. CA Cancer J Clin. 1999;49(1):33-64. 
3. Adebamowo CA, Ajayi OO. Breast Cancer in Nigeria. West Afr J Med. 2000;19:179-191.

4. Anyanwu SNC. Breast Cancer in Eastern Nigeria. West Afr J Med. 2000;19:120-125.

5. Smith RA, Caleffi M, Albert US, et al. Breast cancer in limitedresource countries: early detection and access to care. Breast J. 2006;12 (Suppl 1):S16-S26.

6. Havers VL, Harlan LC, Stevens JL. Racial/ethnic variation in clinical presentation, treatment, and survival among breast cancer patients under age 35. Cancer. 2003;97(1):134-147.

7. Nyagol J, Nyong'o A, Byakika B, et al. Routine assessment of hormonal receptor and her-2/neu status underscores the need for more therapeutic targets in Kenyan women with breast. cancer. Anal Quant Cytol Histol. 2006;28:97-103.

8. Ikpatt OF, Ndoma-Egba R. Oestrogen and progesterone receptors in Nigerian breast cancer: relationship to tumour histology and survival of patients. Cent Afr J Med. 2003;49:122-126.

9. Mbonde MP, Amir H, Schwartz-Albiez R, et al. Expression of estrogen and progesterone receptors in carcinomas of the female breast in Tanzania. Oncol Rep. 2000;7:277-283.

10. Most recent estimates of the cancer incidence, mortality and prevalence, by sex and cancer site, for all the countries of the world (GLOBOCAN 2002). http://www-dep.iarc.fr/.

11. Amir H, Kitinya JN, Parkin DM. A comparative study of carcinoma of the breast in an African population. East Afr Med J. 1994;71(4):215-218.

12. Anyanwu SN. Survival following treatment of primary breast cancer in eastern Nigeria. East Afr Med J. 2000;77(10):539-543.

13. Hassan I, Onukak EE, Mabogunje OA. Breast cancer in Zaria, Nigeria. J R Coll Surg Edinb. 1992;37(3):159-161.

14. Jatoi I, Anderson WF, Rao SR, Devesa SS. Breast cancer trends among black and white women in the United States. J Clin Oncol. 2005;23(31):7836-7841.
15. Carey LA, Perou CM, Livasy CA, et al. Race, breast cancer subtypes, and survival in the Carolina Breast Cancer Study. JAMA. 2006;295(21):2492-2502

16. Bowen RL, Duffy SW, Ryan DA, Hart IR, Jones JL. Early onset of breast cancer in a group of British black women. Br J Cancer. 2008;98(2):277-281.

17. Pathak DR, Osuch JR, He J. Breast carcinoma etiology: current knowledge and new insights into the effects of reproductive and hormonal risk factors in black and white populations. Cancer. 2000;88(Suppl):1230-1238.

18. Palmer JR, Wise LA, Horton NJ, et al. Dual effect of parity on breast cancer risk in African-American women. J Natl Cancer Inst. 2003;95:478-483.

19. Muguti GI. Experience with breast cancer in Zimbabwe. J R Coll Surg Edinb. 1993;38(2):75-78.

20. Pillay AL. Rural and urban South African women's awareness of cancers of the breast and cervix. Ethn Health. 2002;7(2):103-114.

21. Wright SV. An investigation into the causes of absconding among black African breast cancer patients. S Afr Med J. 1997;87(11):1540-1543.

22. Vorobiof DA, Sitas F, Vorobiof G. Breast cancer incidence in South Africa. J Clin Oncol. 200119(18 Suppl):125S-127S.

23. Mbonde MP, Amir H, Schwartz-Albiez R, Akslen LA, Kitinya JN. Expression of estrogen and progesterone receptors in carcinomas of the female breast in Tanzania. Oncol Rep. 2000;7(2):277-283.

24. Gukas ID, Jennings BA, Mandong BM, et al. Clinicopathological features and molecular markers of breast cancer in Jos, Nigeria. West Afr J Med. 2005;24(3):209-213.

25. Furberg H, Millikan R, Dressler L, Newman B, Geradts J. Tumor characteristics in African American and white women. Breast Cancer Res Treat. 2001;68(1):33-43.
International Journal of Women's Health

\section{Publish your work in this journal}

The International Journal of Women's Health is an international, peerreviewed open-access journal publishing original research, reports, reviews and commentaries on all aspects of women's healthcare including gynaecology, obstetrics, and breast cancer. Subject areas include: Chronic conditions (migraine headaches, arthritis, osteoporosis);

\section{Dovepress}

Endocrine and autoimmune syndromes; Sexual and reproductive health; Psychological and psychosocial conditions. The manuscript management system is completely online and includes a very quick and fair peer-review system. Visit http://www.dovepress.com/ testimonials.php to read real quotes from published authors. 